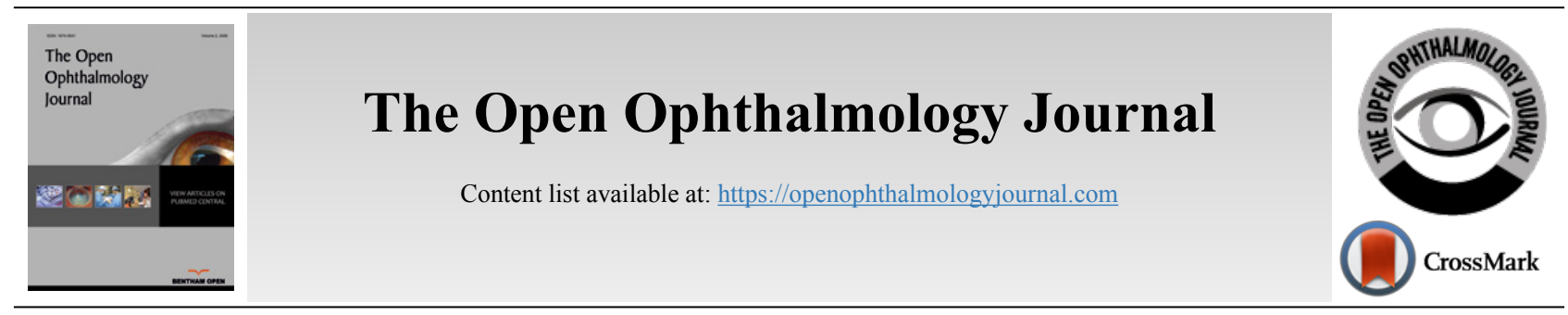

RESEARCH ARTICLE

\title{
Ethnic Differences of Corneal Parameters: A Cross-Sectional Study
}

\author{
Ali Alsaqr ${ }^{1, *}$, Raied Fagehi ${ }^{1}$, Ali Abu Sharha ${ }^{1}$, May Alkhudair ${ }^{1}$, Abrar Alshabrami $^{1}$, Alhanouf Bin Muammar ${ }^{1}$, Sultan
} Abdulwahed $^{1}$ and Ali Alshehri ${ }^{1}$

${ }^{1}$ Department of Optometry, College of Applied Medical Sciences, King Saud University, Saudi Arabia

\begin{abstract}
:
Purpose:

To investigate the ethnic differences of corneal parameters in Arabs and other ethnicities.

Methods:

This study recruited 250 Saudi Arabian participants, 18-45 years of age. The McMonnies questionnaire was used to exclude participants with dry eye. The KR8800 auto refractometer (Topcon, Japan) was used to measure the refractive error. Oculus Keratograph 4 topography was used to assess 16 corneal parameters, including the k-readings, horizontal visible iris diameter, mean eccentricity index, asphericity, corneal shape factor, corneal flattening factor, sagittal height, sagittal curvature, and vertical palpebral aperture.

Results:

A statistically significant difference was found between male and female participants. Corneal parameters were compared to other ethnicities, including Caucasians and Asians, and those of Mongoloid origin. The horizontal visible iris diameter was wider in Saudi Arabians than in Asians but similar to Caucasians. The sagittal height was deeper and the corneal shape factor was higher than in the other ethnicities, and the eccentricity index was lower than that in Caucasians and Asians of Mongoloid origin.

\section{Conclusion:}

Our data provided normative corneal parameters of Saudi Arabians that may be useful for ophthalmic clinicians and designers of contact lenses. Furthermore, the parameters suggest that the corneal characteristics of Arabians are distinct from those of major ethnicities.
\end{abstract}

Keywords: Cornea, Corneal shape, Asphericity, Corneal eccentricity, Ethnicity, Saudi, Middle eastern.

\begin{tabular}{ll|l|r} 
Article History & Received: July 8, 2020 & Revised: October 27, 2020 & Accepted: November 3, 2020
\end{tabular}

\section{INTRODUCTION}

Light passes through the cornea, whose layers direct it towards the pupil. ${ }^{1}$ The cornea is responsible for approximately two-thirds of the eye's refractive power, which results from its shape and the marked difference between the cornea refractive index (1.376) and air (1) [1].

Corneal shape and functionality can be determined using several corneal parameters, which are crucial for diagnostic, therapeutic, and management purposes. These parameters include corneal diameter (CD), which is also termed horizontal or vertical visible iris diameter (HVID), anterior corneal curvature (ACC), and central corneal thickness (CCT). For

\footnotetext{
* Address correspondence to this author at Department of Optometry, College of Applied Medical Sciences, King Saud University, Saudi Arabia; Tel: 00966553497786; Fax: 00966114693536; E-mail: aalsaqr@ksu.edu.sa
}

example, the proper selection of corrective contact lens (CL) parameters depends mainly on $\mathrm{CD}$ and ACC [2]. Furthermore, a cornea that is too curved is found in keratoconus, and a cornea that is too flat is found in conditions such as severe refractive errors [3]. Such differences in topography may lead to differences in CL fitting success rates [4 - 8]. The conicoid shape is also of importance in determining CL design [9].

There are several factors that influence corneal parameters, including ethnicity (social groups who have the same race), age, sex, race, axial length, and refractive status of the eye, in addition to certain anthropometric factors [10]. Scientists and optometrists practice in a multi-ethnic society, which could raise concern if a lens design for a patient from a certain ethnicity is not compatible with another patient from a different ethnicity. For example, anatomical differences have been noted between Asian and Caucasian eyes. These differences include 
narrower palpebral fissure and epicanthal folds in Asian adults [11].

People differ from each other based on hereditary differences, genetic differences, and differences in their exposure to the environment [12]. Genetic physical features characterize an ethnic group and are classified based on various characteristics such as facial characteristics, including the appearance and form of the exterior eye. People are widely classified into three major ethnic groups: Caucasoid, Negroid, and Mongoloid [13].

The Caucasoids are the major inhabitants of Europe and North America. In general, they have large double eyelids, exposed tear troughs, and light eyes. Negroids are the principal inhabitants of Africa. Their facial features involve large eyes and dark irises with exposed tear troughs. Finally, Mongoloids mainly live in Asia. Their principal facial features include narrow eyes, usually with dark irises and epicanthic folds.

However, large and highly diverse macro-ethnic groups such as Australoids, East Indians, North Africans, Brazilians, and Middle Easterners (Arabs) are sometimes presumptively grouped as Caucasoids or Mongoloids. This classification might not be accurate. The term "Arab" originally referred to the inhabitants of the northern and central portions of the Arabian Peninsula. The Arabs constitute the majority ethnic group in all Middle East countries.

There have been significant technological improvements in measuring ocular parameters and a subsequently increased interest in the measurement of corneal parameters in recent years. Several studies have investigated ocular topography in specific ethnic groups [14 - 19] and several have drawn comparisons between ethnicities [7, 20 - 24]. However, none have focused on subjects with an Arabian background, and all of them have tended to use simple clinical measurement outcomes (e.g., CCT and ACC) using simple instruments. Furthermore, the results of these studies have not been consistent; the majority have suggested steeper corneas in Asians compared to Caucasian eyes [6, 12, 23], while one study found the opposite [8], and one study comparing Japanese and Caucasians in the USA found no difference [2]. In addition, previous studies have reported smaller PA sizes in Asians compared to Caucasians [2, 8, 18, 19, 23 - 26].

We investigated the corneal parameters of Saudi Arabians (the main inhabitants of the Arabic peninsula in modern history) and characterized the differences in corneal topography between Saudi Arabians and various ethnic groups. Understanding these differences might help clinicians assess CL performance (e.g., fit and comfort) and might also help optimize CL designs for specific ethnicities.

\section{METHODS}

Ethical approval was obtained from the Research Ethics Committee at “...". All procedures followed the tenets of the Declaration of Helsinki. The participants were recruited at two locations at “...". Informed consent was obtained from all participants after the explanation of the aims of the study and all procedures to be undertaken.
This was a prospective cross-sectional study. To facilitate analyses and comparisons to other studies, all participants were 18-45 years of age to minimize the ocular effects of aging, such as sagging lids and pingueculae. The participants were recruited based on the absence of any history of corneal disorders and/or lid abnormalities, had not previously undergone ocular surgery, and did not wear CL during at least the previous 3 months. The participants were not sex or age specific, and were randomly selected from those of Saudi Arabian ethnicity. All corneal images were of the right eye; this is to avoid any eventual correlation existing between the right and left eyes of a single patient [27, 28].

All participants also completed the McMonnies questionnaire, were checked for the presence of dry eye and palpebral fissure height measurements, measured for distance visual acuity (VA) with their best correction (if any), checked for objective refraction using an auto-refractometer, and checked for corneal topography using keratography.

\subsection{Instrumentation}

The McMonnies questionnaire was used to detect the presence or absence of dry eye. It included 12 questions that focus on risk factors for dry eye [29]. The reliability, validity, and accuracy of the McMonnies Index have been previously investigated [30]. The dryness cutoff was set at $>14.50$.

The VA was measured using the Early Treatment Diabetic Retinopathy Study (ETDRS) Acuity chart at a test distance of 4 $\mathrm{m}$, with a normal level of light. The chart was a nonilluminated ETDRS with Sloan letters (Precision Vision, La Salle, IL, USA). The VA was measured monocularly with the participant's habitual corrections, if applicable. To detect the spherical power, the Auto-Refractometer KR-8800 (Topcon, Tokyo, Japan) was used, while the astigmatic power used the Keratograph 4 (Oculus Optikgeräte, Wetzlar, Germany).

The Keratograph 4 was used to objectively evaluate the ocular surface, involving the corneal topography based on Placido ring illumination equipped with an infrared illumination system $(880 \mathrm{~nm})$ with 22 rings that evaluated 22,000 points on the anterior corneal surface. Keratograph 4 is a non-contact and noninvasive device, which does not require a topical anesthetic, and provides a rapid and easy clinical method that results in a variety of non-contact corneal imaging information, CL fitting, and pupil reaction assessment tools that are repeatable and valuable [31,32]. The Keratograph 4 provides several outcomes such as tear film quality based on noninvasive keratograph tear film breakup time, quantity (tear meniscus), pre- and postoperative measurements, and the amount of corneal irregularities using Fourier analyses as well as keratoconus detection. We used the refractive and corneal asphericity maps (Fig. 1). The approximate time taken for visualization of both maps was 1-2 min, which did not require extensive training to operate the device.

The participants were seated comfortably and asked to focus on the central target, and to blink completely just before each measurement to spread an optically smooth tear film over the cornea. 

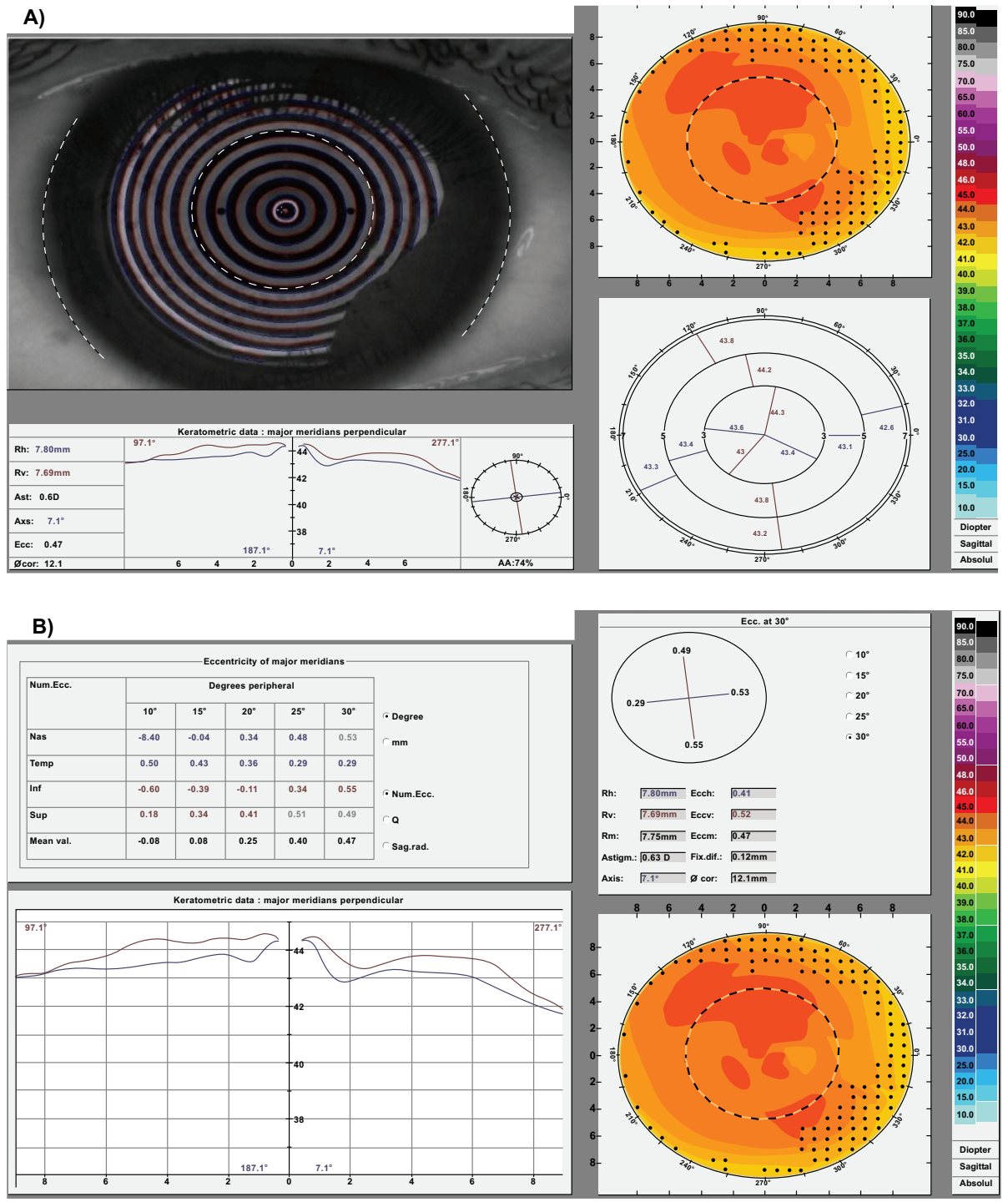

Fig. (1). A) The Keratograph 4 overview of the refractive map of one of our participants, where Rh, Rv, and astigmatism were recorded. B) The corneal asphericity map which shows the eccentricity, S.RadM and Q values at different locations.

\subsection{Assessment of Refractive and $Q$ Maps Using the Keratograph 4}

The corneal shape can be mathematically interpreted using several parameters, which have previously been described [33, 34]. Some of the parameters used in this study are described in detail in Table $\mathbf{1}$

Table 1. The corneal parameters as collected from the Oculus Keratograph 4.

\begin{tabular}{|c|c|}
\hline Variable & Definition \\
\hline (PA) & The distance between the upper and lower lid (mm) while normally opening the eyes. \\
\hline (HVID) & Horizontal limbus-to-limbus distance. \\
\hline (Rh) & Simulated keratometry in the horizontal meridian in the $3.00 \mathrm{~mm}$ zone. \\
\hline$(\mathrm{Rv})$ & Simulated keratometry in the vertical meridian in the $3.00 \mathrm{~mm}$ zone. \\
\hline (Astig) & The difference between the simulated keratometry in the horizontal and vertical meridians in the $3.00 \mathrm{~mm}$ zone. \\
\hline $\begin{array}{l}\text { (e) } @ 30^{\circ}(10 \\
\mathrm{mm} \text { from the } \\
\text { center })\end{array}$ & $\begin{array}{l}\text { Measures the rate of corneal flattening (applanation) from the apex to the periphery along a specific axis. We measured the mean } \\
\text { eccentricity, horizontal eccentricity, and vertical eccentricity. Corneas that flattened at a greater rate from the center outward were } \\
\text { assigned high e-values, and those that flattened at a lesser rate have low e-values. Spherical corneas had low e-values compared to } \\
\text { keratoconic corneas, which had a much steeper apex and flattened at a greater rate toward the periphery. The eccentricity was also } \\
\text { an indicator of corneal sagittal height. Corneas with lower e-values had a greater sagittal height, while corneas with higher e-values } \\
\text { had a lower sagittal height. }\end{array}$ \\
\hline
\end{tabular}




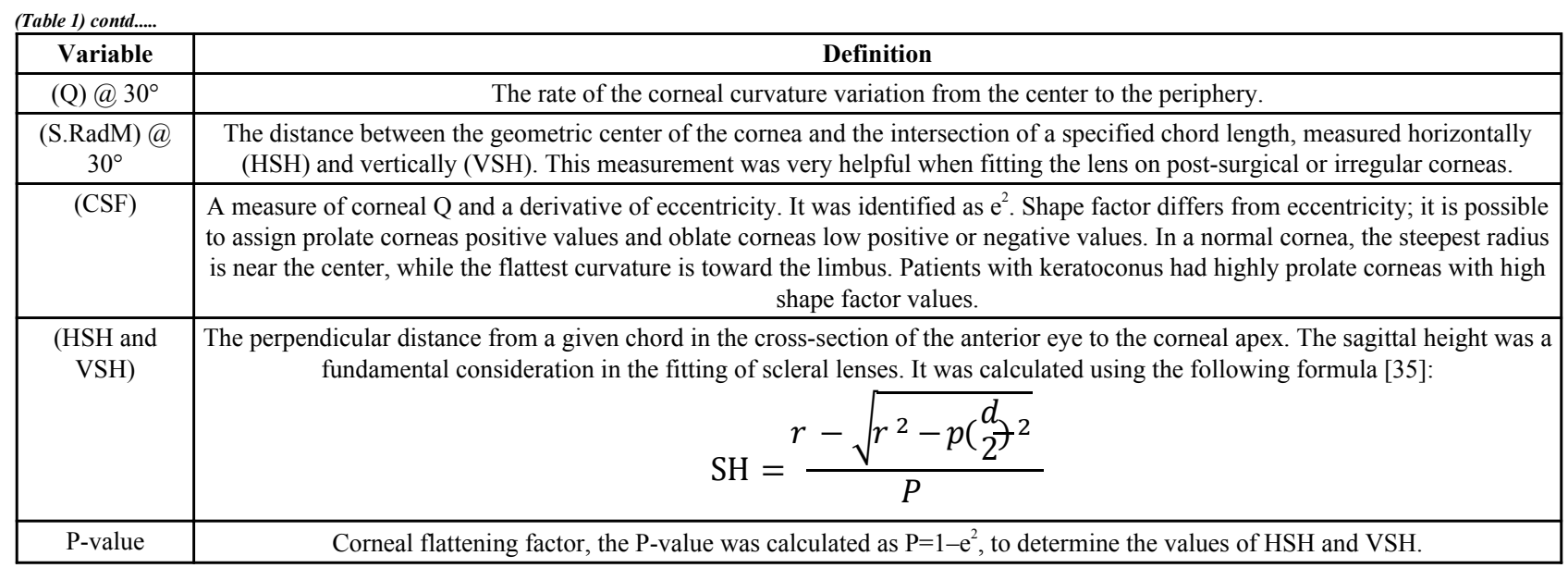
**PA, Vertical palpebral aperture, HVID, Horizontal visible iris diameter, Rh, Horizontal radius, Ry, Vertical radius, Astig, Astigmatism, e, Eccentricity, Q, Asphericity coefficient, S.RadM, Corneal sagittal curvature, CSF, Corneal shape factor, HSH and VSH, horizontal and vertical sagittal height.

\section{RESULTS}

\subsection{Data Analyses}

Starting with 254 eligible participants, only 4 participants were excluded because of CL wear, ptosis, or refractive surgery, leaving a total of 250 participants ( 80 males and 170 females). The data were not normally distributed; therefore, the median and interquartile range (M and IQR, respectively) are used to report the data.

\subsection{Characteristics of the Participants}

This study included young adult and middle-aged participants, 18-45 years old, with M and IQR of 23.31 and 4.93 , respectively. The VA of all participants was better than $6 / 9$ with or without correction, the spherical refractive error ranged from $+3.00 \mathrm{D}$ to $-3.00 \mathrm{D}$ (Median $\pm \mathrm{IQR},-0.75 \mathrm{D} \pm 1.7$ D). Of the participants, $27 \%$ were emmetropic, $30 \%$ were myopic with $>-0.50$ to $-1.50 \mathrm{D}, 30 \%$ were myopic with $>-1.50$ to $-3.00 \mathrm{D}$ and $13 \%$ were hyperopic with $>0.50 \mathrm{D}$ to $3 \mathrm{D}$. The astigmatism ranged from 0 to $-3.00 \mathrm{DC}$, with only $10 \%$ of the participants had astigmatism $>1.00$ DC. Of the participants, $55 \%$ have with the rule astigmatism, $20 \%$ have against the rule astigmatism and $25 \%$ have oblique astigmatism.

\subsection{Corneal Parameters}

The in-depth corneal parameters are described in Table $\mathbf{2}$. Briefly, the PA ranged from $8 \mathrm{~mm}$ up to $14 \mathrm{~mm}$, while the HVID was relatively large, starting from 10.80 to $13.60 \mathrm{~mm}$. The Rh and the Rv were similar to each other: 7.25-9.10 mm (37.00 D to $46.50 \mathrm{D})$ and $7.10-8.79 \mathrm{~mm}(38.25 \mathrm{D}$ to $47.50 \mathrm{D})$, respectively. Maximum astigmatism noted was $3.00 \mathrm{DC}$, although the majority of the participants had minimal astigmatism, with $70 \%$ of the participants having astigmatism of $\leq 1.00 \mathrm{DC}$.

Table 2. A summary of the corneal parameters as a function of gender and overall scores.

\begin{tabular}{|c|c|c|c|c|}
\hline Corneal Parameter & Male & Female & Overall & Gender Difference \\
\hline & $\begin{array}{c}\text { Mean (SD) } \\
\text { Range }\end{array}$ & $\begin{array}{c}\text { Mean (SD) } \\
\text { Range }\end{array}$ & $\begin{array}{c}\text { Mean (SD) } \\
\text { Range }\end{array}$ & Mann-Whitney test, $\mathrm{p}$ value \\
\hline No. subjects (eyes) & $80(80)$ & $170(170)$ & $250(250)$ & -- \\
\hline Age (Years) & $\begin{array}{c}24.12(3.99) \\
18-38 \\
\end{array}$ & $\begin{array}{c}22.50(5.9) \\
19-45 \\
\end{array}$ & $\begin{array}{c}23.31(4.93) \\
18-45 \\
\end{array}$ & $\mathrm{z}=-0.28, \mathrm{p}=0.78$ \\
\hline $\mathbf{P A}, \mathbf{m m}$ & $\begin{array}{l}11.60(0.56) \\
10.2013 .20\end{array}$ & $\begin{array}{c}11.1(1.21) \\
8-14\end{array}$ & $\begin{array}{c}11.25(1.1) \\
8-14\end{array}$ & $\mathrm{z}=-4.44, \mathrm{p}<0.001^{*}$ \\
\hline HVID, mm & $\begin{array}{c}12.11(.41) \\
11.00-13.00\end{array}$ & $\begin{array}{c}11.94(0.41) \\
10.80-13.60\end{array}$ & $\begin{array}{c}11.99(0.41) \\
10.80-13.60 \\
\end{array}$ & $\mathrm{z}=-2.77, \mathrm{p}=0.006^{*}$ \\
\hline Pupil Size, mm & $\begin{array}{c}3.65(0.60) \\
2.00-5.00\end{array}$ & $\begin{array}{c}3.5(.61) \\
2.20-5.70\end{array}$ & $\begin{array}{c}3.57(0.61) \\
2-5\end{array}$ & $\mathrm{z}=-2.13, \mathrm{p}=0.033^{*}$ \\
\hline Rh, $\mathbf{m m}$ & $\begin{array}{l}8.00(0.31) \\
7.25-9.10\end{array}$ & $\begin{array}{l}7.92(0.28) \\
7.26-8.85\end{array}$ & $\begin{array}{l}7.94(0.29) \\
7.25-9.10\end{array}$ & $\mathrm{z}=-2.1, \mathrm{p}=0.037^{*}$ \\
\hline Rv, mm & $\begin{array}{l}7.84(0.29) \\
7.12-8.65 \\
\end{array}$ & $\begin{array}{l}7.75(0.29) \\
7.08-8.79 \\
\end{array}$ & $\begin{array}{l}7.77(0.29) \\
7.10-8.79 \\
\end{array}$ & $\mathrm{z}=-2.21, \mathrm{p}=0.027^{*}$ \\
\hline Astig, Cylindrical Diopter & $\begin{array}{l}0.90(0.55) \\
0.10-2.45\end{array}$ & $\begin{array}{l}0.92(0.58) \\
0.10-3.00\end{array}$ & $\begin{array}{l}0.91(0.57) \\
0.01-3.00 \\
\end{array}$ & $\mathrm{z}=-0.04, \mathrm{p}=0.97$ \\
\hline Overall Mean (e) index & $\begin{array}{c}0.51(0.15) \\
-0.50-0.75\end{array}$ & $\begin{array}{c}0.57(0.11) \\
0.14--0.95\end{array}$ & $\begin{array}{c}0.55(0.13) \\
-0.50--0.95\end{array}$ & $\mathrm{z}=-4.1, \mathrm{p}<0.001 *$ \\
\hline Horizontal (e) index & $\begin{array}{c}0.51(0.15) \\
-0.49-0.74\end{array}$ & $\begin{array}{l}0.58(0.10) \\
0.30-0.93\end{array}$ & $\begin{array}{c}0.56(0.12) \\
-0.49-0.93\end{array}$ & $\mathrm{z}=-3.89, \mathrm{p}<0.0001^{*}$ \\
\hline
\end{tabular}


(Table 2) contd.....

\begin{tabular}{|c|c|c|c|c|}
\hline Corneal Parameter & Male & Female & Overall & Gender Difference \\
\hline Vertical (e) index & $\begin{array}{c}0.50(0.17) \\
-0.51-0.76\end{array}$ & $\begin{array}{c}0.57(0.14) \\
-0.03-0.98\end{array}$ & $\begin{array}{c}0.56(0.16) \\
-0.51-0.98\end{array}$ & $\mathrm{z}=-3.52, \mathrm{p}<0.0001^{*}$ \\
\hline Asphericity (Q) & $\begin{array}{c}-0.29(0.12) \\
-0.61--0.09\end{array}$ & $\begin{array}{l}-0.36(0.13) \\
-0.92--0.04\end{array}$ & $\begin{array}{c}-0.33(0.13) \\
-0.92--0.09\end{array}$ & $\mathrm{z}=-2.32, \mathrm{p}=0.024^{*}$ \\
\hline CSF & $\begin{array}{l}0.28(0.10) \\
0.08-0.56\end{array}$ & $\begin{array}{l}0.34(0.13) \\
0.02-0.90\end{array}$ & $\begin{array}{l}0.32(0.12) \\
0.02-0.90\end{array}$ & $\mathrm{z}=-3.90, \mathrm{p}<0.0001 *$ \\
\hline Horizontal, CSF & $\begin{array}{l}0.29(0.10) \\
0.12-0.55\end{array}$ & $\begin{array}{l}0.34(0.12) \\
0.09-0.86\end{array}$ & $\begin{array}{l}0.33(0.12) \\
0.09-0.86\end{array}$ & $\mathrm{z}=-3.86, \mathrm{p}<0.0001 *$ \\
\hline Vertical, CSF & $\begin{array}{c}0.28(0.11) \\
0-0.57\end{array}$ & $\begin{array}{c}0.35(0.15) \\
0-0.95\end{array}$ & $\begin{array}{c}0.33(0.14) \\
0-0.95\end{array}$ & $\mathrm{z}=-3.44, \mathrm{p}=0.001^{*}$ \\
\hline $\mathbf{P}$ & $\begin{array}{l}0.71(0.10) \\
0.44-0.92 \\
\end{array}$ & $\begin{array}{l}0.66(0.13) \\
0.10-0.98\end{array}$ & $\begin{array}{l}0.68(0.12) \\
0.10-0.98\end{array}$ & $\mathrm{z}=-3.47, \mathrm{p}=0.001^{*}$ \\
\hline HSH, mm & $\begin{array}{c}2.59(0.18) \\
2.1-3.1\end{array}$ & $\begin{array}{l}2.53(0.21) \\
2.01-3.30\end{array}$ & $\begin{array}{l}2.55(0.21) \\
2.01-3.30\end{array}$ & $\mathrm{z}=-2.39, \mathrm{p}=0.017 *$ \\
\hline VSH, mm & $\begin{array}{l}2.66(0.19) \\
2.12-3.16 \\
\end{array}$ & $\begin{array}{l}2.60(0.22) \\
1.99-3.33 \\
\end{array}$ & $\begin{array}{l}2.62(0.22) \\
1.99-3.33 \\
\end{array}$ & $\mathrm{z}=-2.62, \mathrm{p}=0.009^{*}$ \\
\hline S.RadM & $\begin{array}{l}8.14(0.31) \\
7.40-9.53\end{array}$ & $\begin{array}{l}8.16(0.34) \\
7.38-9.35\end{array}$ & $\begin{array}{l}8.15(0.33) \\
7.38-9.35\end{array}$ & $\mathrm{z}=-0.51, \mathrm{p}=0.61$ \\
\hline
\end{tabular}

* indicates the statistical difference between the two genders, PA, palpebral aperture; HVID, horizontal visible iris diameter; Rh, horizontal radius; Rv, vertical radius; Astig, astigmatism; (e), numerical eccentricity mean value of $30^{\circ}$; (Q), asphericity value of $30^{\circ}$; CSF, corneal shape factor; P, corneal flattening factor; HSH, horizontal sagittal height; VSH, vertical sagittal height; S.RadM, sagittal curvature value of $30^{\circ}$.

Table 2 shows the median applanation rate (or eccentricity index, e); the horizontal and vertical at $30^{\circ}$ were approximately 0.55 . The corneal $(\mathrm{Q})$ at $30^{\circ}$ was -0.33 . The corneal shape factors varied between 0.02 and 0.90 , which indicated that all participants had prolate corneas. The horizontal and vertical sagittal heights ranged from 2.01 to 3.30 and 1.99 to $3.33 \mathrm{~mm}$, respectively. The corneal sagittal curvature was $7.38-9.35 \mathrm{~mm}$. Corneal parameters statistically significantly differed by sex (Table 2).

\subsection{The Ethnicity Factor}

The parameters were compared to the results of previous studies that investigated other ethnicities (Table 3). The average PA in our population was larger than that found in previous studies (Table 3), but similar to a group with an African background [36]. The average corneal curvatures (Rh and $\mathrm{Vh}$ ) were similar to previous studies (Table $\mathbf{1}$ and Table $\mathbf{3}$ in a previous study [7]). The average HVID was wider than that in Asians but similar to Caucasians (Table 3 and a previous study [37]). The calculated HSH and VSH were deeper than those of other ethnicities, which explains the strong relationship between sagittal height and HVID ( $\mathrm{r}=0.74, p<$ 0.0001). The median CSFs were higher (i.e., greater Q) than reported in some previous studies for other ethnicities (Table 3). The eccentricity index was lower than that in a previous study (Caucasian and Mongoloid), which indicates a slower flattening rate. ${ }^{12}$ The $\mathrm{Q}$ was similar to that previously found in the Chinese population [19].

Table 3. Comparison of corneal parameters noted in this study with their matching parameters in other ethnicities.

\begin{tabular}{|c|c|c|c|c|c|c|}
\hline \multirow{2}{*}{$\begin{array}{c}\text { Study } \\
\text { Race/ ethnicity }\end{array}$} & \multirow{2}{*}{$\begin{array}{c}\text { Current study } \\
\text { Saudi Arabs }\end{array}$} & \multicolumn{3}{|c|}{ Hickson-Curran et al. ${ }^{4}$} & \multicolumn{2}{|c|}{ Loran et al. ${ }^{12}$} \\
\hline & & White & Chinese & Japanese & Caucasian & Mongoloid \\
\hline \multirow{2}{*}{ Variable } & Median (IQR) & Mean (SD) & Mean (SD) & Mean (SD) & Mean (SD) & Mean (SD) \\
\hline & Range & Range & Range & Range & Range & Range \\
\hline \multirow{2}{*}{ AGE (Years) } & $23.31(4.93)$ & $31.9(7.4)$ & $28.0(5.5)$ & $33.4(4.8)$ & \multirow{2}{*}{$18-35$} & \multirow{2}{*}{$18-35$} \\
\hline & $18-45$ & $18-45$ & $18-45$ & $24-44$ & & \\
\hline No. subjects (eyes) & $250(250)$ & $255(510)$ & $299(598)$ & $121(242)$ & 100 (NR) & 100 (NR) \\
\hline \multirow{2}{*}{ PA } & $11.25(1.1)$ & $10.58(1.43)$ & $9.71(1.28)$ & $10.31(1.30)$ & \multirow{2}{*}{ NR } & \multirow{2}{*}{ NR } \\
\hline & Aug-14 & $6.56-14.60$ & $6.06-13.40$ & $7.90-13.10$ & & \\
\hline \multirow{2}{*}{ HVID, mm } & $11.99(0.41)$ & $11.75(0.50)$ & $11.26(0.43)$ & $11.10(0.41)$ & \multirow{2}{*}{ NR } & \multirow{2}{*}{ NR } \\
\hline & $10.80-13.60$ & $10.58-13.08$ & $9.98-12.57$ & $10.04-12.31$ & & \\
\hline \multirow{2}{*}{$\mathbf{R h}, \mathbf{m m}$} & $7.94(0.29)$ & $7.79(0.27)$ & $7.86(0.23)$ & $7.92(0.23)$ & $7.88(0.29)$ & $7.79(0.29)$ \\
\hline & $7.25-9.10$ & $6.92-8.60$ & $7.18-8.49$ & $7.30-8.60$ & NR & NR \\
\hline \multirow{2}{*}{$\mathbf{R v}, \mathbf{m m}$} & $7.77(0.29)$ & $7.65(0.28)$ & $7.67(0.25)$ & $7.71(0.26)$ & $7.75(0.19)$ & $7.63(0.22)$ \\
\hline & $7.10-8.79$ & $6.44-8.44$ & $7.01-8.41$ & $6.99-8.39$ & NR & NR \\
\hline \multirow{2}{*}{ HSH, mm } & $2.55(0.21)$ & $1.74(0.08)$ & $1.65(0.07)$ & $1.71(0.07)$ & \multirow{2}{*}{ NR } & \multirow{2}{*}{ NR } \\
\hline & $2.01-3.30$ & $1.39-2.02$ & $1.37-1.89$ & $1.48-1.91$ & & \\
\hline \multirow{2}{*}{ VSH, mm } & $2.62(0.22)$ & $1.80(0.09)$ & $1.68(0.08)$ & $1.78(0.08)$ & \multirow{2}{*}{ NR } & \multirow{2}{*}{ NR } \\
\hline & $1.99-3.33$ & $1.45-2.08$ & $1.37-1.95$ & $1.55-2.0$ & & \\
\hline
\end{tabular}


(Table 3) contd....

\begin{tabular}{|c|c|c|c|c|c|c|}
\hline Study & Current study & \multicolumn{3}{|c|}{ Hickson-Curran et al. ${ }^{4}$} & \multicolumn{2}{|c|}{ Loran et al. $^{12}$} \\
\hline \multirow{2}{*}{ HCSF } & $0.33(0.12)$ & $0.40(0.20)$ & $0.41(0.19)$ & $0.43(0.17)$ & \multirow{2}{*}{$0.20(0.03)$} & \multirow{2}{*}{$0.12(0.08)$} \\
\hline & $0.09-0.86$ & -1.9 & $0.02-0.97$ & -1.73 & & \\
\hline \multirow{2}{*}{ VCSF } & $0.33(0.14)$ & $0.24(0.16)$ & $0.34(0.16)$ & $0.20(0.13)$ & \multirow{2}{*}{ NR } & \multirow{2}{*}{ NR } \\
\hline & $0-0.95$ & -1.74 & $0.00-0.81$ & $0.00-1.00$ & & \\
\hline \multirow{2}{*}{ Eccentricity Index } & $0.55(0.13)$ & \multirow{2}{*}{--} & \multirow{2}{*}{--} & \multirow{2}{*}{--} & \multirow{2}{*}{0.8} & \multirow{2}{*}{0.88} \\
\hline & 0.45 & & & & & \\
\hline
\end{tabular}

*NR, not recorded

\section{DISCUSSION}

Several studies have investigated corneal parameters, but they have focused merely on corneal power, diameter, or thickness [20, 38 - 43]; very few studies have investigated corneal parameters in more depth [10].

Ocular topography measurements are usually associated with CL practice, and thus we evaluated different ocular topography variables. Several normative corneal parameters were measured. To be representative of normal corneas, all participants recruited had a good VA and had only mild astigmatism. There were more female participants than male participants, so this was a limitation of the study. The reason may have been that females were more willing to volunteer, as we did not reimburse them for their time. The association between participant gender and corneal parameters was significant, consistent with previous findings [2, 7]. Furthermore, previous studies that investigated ethnicities and corneal characteristics varied widely in terms of the participants' refractive error. In details, Loran et al. included myopic participants with < 4 D [12], Matsuda et al. did not report the refractive status of their study participants [2] and Hickson-Curran et al. included participants with wider refractive errors than the current study where the refractive error ranged from $-26 \mathrm{D}$ to $+7 \mathrm{D}$ [7]. Therefore, it was very challenging to compare the outcome of this study in terms of the refractive status with respect to previous studies and this could be another limitation in this study as well as previous studies.

Numerous studies have reported a correlation between corneal SH and soft lens centration, with increasing corneal SH at $30^{\circ}(10 \mathrm{~mm})$ being associated with greater CL decentration. Accordingly, the change in the lens base curve should be considered when designing the best centration. Therefore, it is important for the soft CL fitter/designer to have the whole corneal profile for a specific ethnicity. Lindsay et al. reviewed previous studies and reported that the mean $Q$ values ranged from -0.03 to -0.33 [33]. The mean $Q$ values in our study ranged from -0.92 to -0.09 . It has been suggested that ethnicity has an impact on corneal Q [44]. This difference might also be due to differences in refractive errors between studies. Furthermore, this may indicate that participants have more variation in the spherical aberration (lower and higher aberrations) than previously thought [45].

Corneal parameters may significantly differ by ethnicity, and this factor should be considered when fitting CLs [46]. Many studies have characterized corneal parameters in different ethnic groups, such as Chinese, Caucasian, and Japanese populations, although no such studies have included participants with a Saudi Arabian background. Understanding ethnic variation in corneal parameters and the relationship with CL fitting may lead to the development of different CL designs that are more directed to different ethnic populations. Hence, this study explored the differences in corneal topography parameters between Saudi Arabians and other ethnic groups. Our results provide comparative data on additional ocular variables and indicate differences in ocular topographies between Saudi Arabians and other ethnicities.

Saudi Arabians were similar to other ethnicities in corneal curvature but different in the other parameters (e.g., PA of Asians) and similar to other ethnicities in the same parameters (e.g., PA of Africans). Specifically, PA was wider in Saudi Arabians than in Caucasian, Chinese, and Japanese participants (Table 3). This may partially explain the higher prevalence of dry eye in Saudi Arabians, especially in addition to the hot dry weather [47]. Saudi Arabians tended to have a larger HVID compared to Caucasian, Chinese, and Japanese eyes, which is an important factor to consider when choosing a CL. Furthermore, there were significant differences in overall CSH between Saudi Arabians and the other ethnicities. Patients suffering from keratoconus have a high prolate corneal shape. We found that Saudi Arabians have prolate corneas, which might explain the increased incidence of keratoconus cases in Saudi Arabia [48 - 50]. These corneal discrepancies suggest that Saudi Arabians should not be classified under one of the main ethnicities (Caucasian, Asian, or African), but should have their own corneal characteristic classification. However, because we did not have the raw data from the previous studies, we were not able to accurately compare the results.

\section{CONCLUSION}

In conclusion, this study provides a normative portfolio of corneal parameters of Saudi Arabians, which could be used by ophthalmic clinicians for the design of soft CLs. Our data also provided evidence that Saudi Arabians have distinct corneal characteristics that are different from the major ethnicities. Future studies shall implant the normative portfolio reported in this study to build a corneal model suitable for contact lens design and fitting in the Arab population.

\section{ETHICS APPROVAL AND CONSENT TO PARTI- CIPATE}

Not applicable.

\section{HUMAN AND ANIMAL RIGHTS}

No animals/humans were used for studies that are the basis of this research. 


\section{CONSENT FOR PUBLICATION}

All patients participated on a voluntary basis and gave their informed consent.

\section{AVAILABILITY OF DATA AND MATERIALS}

Not applicable.

\section{FUNDING}

None.

\section{CONFLICT OF INTEREST}

The authors declare no conflict of interest, financial or otherwise.

\section{ACKNOWLEDGEMENTS}

The authors extend their appreciation to the College of Applied Medical Sciences Research Centre and the Deanship of Scientific Research at King Saud University for funding this research. The English in this document has been checked by at least two professional editors, both native speakers of English. http://www.textcheck.com/certificate/azZsKz

\section{REFERENCES}

[1] Ruskell GL, Bergmanson JPG. Contact Lenses. 5th ed. Oxford: Butterworth-Heinemann 2006.

[2] Matsuda LM, Woldorff CL, Kame RT, Hayashida JK. Clinical comparison of corneal diameter and curvature in Asian eyes with those of Caucasian eyes. Optom Vis Sci 1992; 69(1): 51-4. [http://dx.doi.org/10.1097/00006324-199201000-00008] [PMID: 1741111]

[3] Denniston AKO, Murray PI. Oxford handbook of ophthalmology (OUP). 2nd ed. Oxford: Oxford University Press 2009.

[4] Hickson-Curran S, Young G, Brennan N, Hunt C. Chinese and Caucasian ocular topography and soft contact lens fit. Clin Exp Optom 2016; 99(2): 149-56

[http://dx.doi.org/10.1111/cxo.12336] [PMID: 26928568]

[5] Kit Wong M, Lee T-t, Tat Poon M, Cho P. Clinical performance and factors affecting the physical fit of a soft toric frequent replacement contact lens 2002; 85

[6] Wong MK, Lee TT, Poon MT, Cho P. Clinical performance and factors affecting the physical fit of a soft toric frequent replacement contact lens. Clin Exp Optom 2002; 85(6): 350-7.

[http://dx.doi.org/10.1111/j.1444-0938.2002.tb02385.x] [PMID: 12452785]

[7] Hickson-Curran S, Brennan NA, Igarashi Y, Young G. Comparative evaluation of Asian and white ocular topography. Optom Vis Sci 2014; 91(12): 1396-405.

[http://dx.doi.org/10.1097/OPX.0000000000000413] [PMID: 25325762]

[8] Lin MC, Chen YQ, Polse KA. The effects of ocular and lens parameters on the postlens tear thickness. Eye Contact Lens 2003; 29(1)(Suppl.): S33-6.

[http://dx.doi.org/10.1097/00140068-200301001-00010] [PMID: 12772727]

[9] Kiely PM, Smith G, Carney LG. The Mean Shape of the Human Cornea. Opt Acta (Lond) 1982; 29: 1027-40 [http://dx.doi.org/10.1080/713820960]

[10] Kang P, Gifford P, McNamara P, et al. Peripheral refraction in different ethnicities. Invest Ophthalmol Vis Sci 2010; 51(11): 6059-65. [http://dx.doi.org/10.1167/iovs.09-4747] [PMID: 20505193]

[11] Whitnall S. Anatomy of the Human Orbit and Accessory Organs of Vision. J Anat 1932; 67: 116-23.

[12] Loran DFC, Lam SY, Frenc CN. An ethnic comparison of anterior segment characteristics: A preliminary report. Journal of The British Contact Lens Association 1984; 7: 158-62. [http://dx.doi.org/10.1016/S0141-7037(84)80020-8]

[13] Hunt EE, Coon CS. The Living Races of Man. Curr Anthropol 1967; 8: $112-26$.
[14] Iyamu E, Osuobeni E. Age, gender, corneal diameter, corneal curvature and central corneal thickness in Nigerians with normal intra ocular pressure. J Optom 2012; 5: 87-97.

[http://dx.doi.org/10.1016/j.optom.2012.02.001]

[15] Nemesure B, Wu SY, Hennis A, Leske MC. Corneal thickness and intraocular pressure in the Barbados eye studies. Arch Ophthalmol $2003 ; 121(2): 240-4$

[http://dx.doi.org/10.1001/archopht.121.2.240] [PMID: 12583791]

[16] Hahn S, Azen S, Ying-Lai M, Varma R. Central corneal thickness in Latinos. Invest Ophthalmol Vis Sci 2003; 44(4): 1508-12. [http://dx.doi.org/10.1167/iovs.02-0641] [PMID: 12657586]

[17] Suzuki S, Suzuki Y, Iwase A, Araie M. Corneal Thickness in an Ophthalmologically Normal Japanese Population. Ophthalmology 112: 1327-36.

[http://dx.doi.org/10.1016/j.ophtha.2005.03.022]

[18] Cheung SW, Cho P, Douthwaite W. Corneal shape of Hong KongChinese. Ophthalmic Physiol Opt 2000; 20(2): 119-25. [http://dx.doi.org/10.1046/j.1475-1313.2000.00488.x] [PMID: 10829134]

[19] Zhang Z, Wang J, Niu W, et al. Corneal asphericity and its related factors in 1052 Chinese subjects. Optom Vis Sci 2011; 88(10): 1232-9. [http://dx.doi.org/10.1097/OPX.0b013e31822717ca] [PMID: 21747308]

[20] Aghaian E, Choe JE, Lin S, Stamper RL. Central corneal thickness of Caucasians, Chinese, Hispanics, Filipinos, African Americans, and Japanese in a glaucoma clinic. Ophthalmology 2004; 111(12): 2211-9. [http://dx.doi.org/10.1016/j.ophtha.2004.06.013] [PMID: 15582076]

[21] Torres RJ, Jones E, Edmunds B, Becker T, Cioffi GA, Mansberger SL. Central corneal thickness in Northwestern American Indians/Alaskan Natives and comparison with White and African-American persons. Am J Ophthalmol 2008; 146(5): 747-51.

[http://dx.doi.org/10.1016/j.ajo.2008.05.047] [PMID: 18672219]

[22] Mercieca K, Odogu V, Fiebai B, Arowolo O, Chukwuka F. Comparing central corneal thickness in a sub-Saharan cohort to African Americans and Afro-Caribbeans. Cornea 2007; 26(5): 557-60. [http://dx.doi.org/10.1097/ICO.0b013e3180415d90] [PMID: 17525651]

[23] Lam CSY, Loran DFC. Designing contact lenses for oriental eyes. Journal of The British Contact Lens Association 1991; 14: 109-14. [http://dx.doi.org/10.1016/0141-7037(91)80003-5]

[24] Qin B, Tang M, Li Y, Zhang X, Chu R, Huang D. Anterior segment dimensions in Asian and Caucasian eyes measured by optical coherence tomography. Ophthalmic Surg Lasers Imaging 2012; 43(2): 135-42.

[http://dx.doi.org/10.3928/15428877-20120102-03]

[PMID: 22320411]

[25] Kikkawa Y. Measurements of corneal diameter and size of palpebral aperture. J Jpn CL Soc 1979; 21: 76-9.

[26] Bao F-J, Yu AY, Kassem W, Wang QM, Elsheikh A. Biometry of the cornea in myopic chinese patients. J Refract Surg 2011; 27(5): 345-55. [http://dx.doi.org/10.3928/1081597X-20101105-02] [PMID 21117538]

[27] Montalbán R, Piñero DP, Javaloy J, Alio JL. Correlation of the corneal toricity between anterior and posterior corneal surfaces in the normal human eye. Cornea 2013; 32(6): 791-8

[http://dx.doi.org/10.1097/ICO.0b013e31827bf898] [PMID: 23328698]

[28] Montalbán R, Piñero DP, Javaloy J, Alió JL. Scheimpflug photography-based clinical characterization of the correlation of the corneal shape between the anterior and posterior corneal surfaces in the normal human eye. J Cataract Refract Surg 2012; 38(11): 1925-33. [http://dx.doi.org/10.1016/j.jcrs.2012.06.050] [PMID: 22981614]

[29] McMonnies C, Ho A, Wakefield D. Lacrimal Gland, Tear Film, and Dry Eye Syndromes 2: Basic Science and Clinical Relevance In: Sullivan DA, Dartt DA, Meneray MA. Advances in Experimental Medicine and Biology. 1998; 438: pp. 835-8.

[30] Nichols KK, Nichols JJ, Mitchell GL. The reliability and validity of McMonnies Dry Eye Index. Cornea 2004; 23(4): 365-71. [http://dx.doi.org/10.1097/00003226-200405000-00010] [PMID: 15097131]

[31] Ortiz-Toquero S, Rodriguez G, de Juan V, Martin R. Repeatability of placido-based corneal topography in keratoconus. Optom Vis Sci 2014; 91(12): 1467-73.

[http://dx.doi.org/10.1097/OPX.0000000000000421] [PMID: 25343684]

[32] Mao X, Savini G, Zhuo Z, et al. Repeatability, reproducibility, and agreement of corneal power measurements obtained with a new 
corneal topographer. J Cataract Refract Surg 2013; 39(10): 1561-9. [http://dx.doi.org/10.1016/j.jcrs.2013.04.029] [PMID: 23860010]

[33] Lindsay R, Smith G, Atchison D. Descriptors of corneal shape. Optom Vis Sci 1998; 75(2): 156-8.

[http://dx.doi.org/10.1097/00006324-199802000-00019] [PMID: 9503441]

[34] Wilson SE, Klyce SD. Quantitative descriptors of corneal topography. A clinical study. Arch Ophthalmol 1991; 109(3): 349-53. [http://dx.doi.org/10.1001/archopht.1991.01080030051037] [PMID: 2003793]

[35] Hall Lee. What You Need to Know About Sagittal Height and Scleral Lenses

https://www.clspectrum.com/issues/2015/may-2015/what-you-need-to -know-about-sagittal-height-and-sc2015.

[36] Patil SB, Kale SM, Math M, Khare N, Sumeet J. Anthropometry of the eyelid and palpebral fissure in an Indian population. Aesthet Surg J 2011; 31(3): 290-4.

[http://dx.doi.org/10.1177/1090820X11398475] [PMID: 21385738]

[37] Mashige K. A review of corneal diameter, curvature and thickness values and influencing factors*. S Afr Optom 2013; 72: 185-94. [http://dx.doi.org/10.4102/aveh.v72i4.58]

[38] Baumeister M, Terzi E, Ekici Y, Kohnen T. Comparison of manual and automated methods to determine horizontal corneal diameter. J Cataract Refract Surg 2004; 30(2): 374-80. [http://dx.doi.org/10.1016/j.jcrs.2003.06.004] [PMID: 15030827]

[39] Piñero DP, Plaza Puche AB, Alió JL. Corneal diameter measurements by corneal topography and angle-to-angle measurements by optical coherence tomography: evaluation of equivalence. J Cataract Refract Surg 2008; 34(1): 126-31.

[http://dx.doi.org/10.1016/j.jcrs.2007.10.010] [PMID: 18165092]

[40] Kohnen T, Thomala MC, Cichocki M, Strenger A. Internal anterior chamber diameter using optical coherence tomography compared with white-to-white distances using automated measurements. J Cataract Refract Surg 2006; 32(11): 1809-13.

[http://dx.doi.org/10.1016/j.jcrs.2006.08.023] [PMID: 17081862]

[41] Rüfer F, Schröder A, Erb C. White-to-white corneal diameter: normal values in healthy humans obtained with the Orbscan II topography system. Cornea 2005; 24(3): 259-61. [http://dx.doi.org/10.1097/01.ico.0000148312.01805.53]

[PMID: 15778595]

[42] Sanchis-Gimeno JA, Sanchez-Zuriaga D, Martinez-Soriano F. Whiteto-white corneal diameter, pupil diameter, central corneal thickness and thinnest corneal thickness values of emmetropic subjects. Surg Radiol Anat 2012; 34(2): 167-70.

[http://dx.doi.org/10.1007/s00276-011-0889-4] [PMID: 22021086]

[43] La Rosa FA, Gross RL, Orengo-Nania S. Central corneal thickness of Caucasians and African Americans in glaucomatous and nonglaucomatous populations. Arch Ophthalmol 2001; 119(1): 23-7. [PMID: 11146722]

[44] Fuller DG, Alperin D. Variations in corneal asphericity (Q value) between African-Americans and whites. Optom Vis Sci 2013; 90(7): 667-73.

[http://dx.doi.org/10.1097/OPX.0b013e318296befe]

[PMID: 23708926]

[45] Calossi A. Corneal asphericity and spherical aberration. J Refract Surg 2007; 23(5): 505-14

[http://dx.doi.org/10.3928/1081-597X-20070501-15] [PMID: 17523514]

[46] Benes P, Synek S, Petrová S. Corneal shape and eccentricity in population. Coll Antropol 2013; 37(Suppl. 1): 117-20. [PMID: 23837229]

[47] Alshamrani AA, Almousa AS, Almulhim AA, et al. Prevalence and Risk Factors of Dry Eye Symptoms in a Saudi Arabian Population. Middle East Afr J Ophthalmol 2017; 24(2): 67-73.

[http://dx.doi.org/10.4103/meajo.MEAJO_281_16] [PMID: 28936049]

[48] Torres Netto E A, et al. Prevalence of keratoconus in paediatric patients in Riyadh, Saudi Arabia. Br J Ophthalmol 2018.

[49] Althomali TA, Al-Qurashi IM, Al-Thagafi SM, Mohammed A, Almalki M. Prevalence of keratoconus among patients seeking laser vision correction in Taif area of Saudi Arabia. Saudi J Ophthalmol 2018; 32(2): 114-8.

[http://dx.doi.org/10.1016/j.sjopt.2017.11.003] [PMID: 29942179]

[50] Assiri AA, Yousuf BI, Quantock AJ, Murphy PJ. Incidence and severity of keratoconus in Asir province, Saudi Arabia. Br J Ophthalmol 2005; 89(11): 1403-6.

[http://dx.doi.org/10.1136/bjo.2005.074955] [PMID: 16234439]

C) 2021 Alsaqr et al.

This is an open access article distributed under the terms of the Creative Commons Attribution 4.0 International Public License (CC-BY 4.0), a copy of which is available at: https://creativecommons.org/licenses/by/4.0/legalcode. This license permits unrestricted use, distribution, and reproduction in any medium, provided the original author and source are credited. 